\title{
Critical Review on Test Case Generation Systems and Techniques
}

\author{
Shivani Kaushik \\ M.Tech Computer Science and Engineering \\ Ajay Kumar Garg Engineering College \\ Ghaziabad, India
}

\author{
Kirti Tyagi \\ Department of Computer Science and Engg. \\ Ajay Kumar Garg Engineering College \\ Ghaziabad, India
}

\begin{abstract}
Software testing has valuable and important place in software development life cycle. It is used to identify the quality and good performance of software. For the software testing phases we have to need the proper test case. Test case may be generated manually and automatically. Generating test case manually will take more time and cost. Automatic test case generation will reduce time and cost. This paper combine review on test case generation systems, object oriented, and procedure oriented and component based development and agent oriented system. This paper also gives the overview on the techniques which is used to generate the test case.
\end{abstract}

\section{Keywords}

test case generation, techniques, specification based, sketch diagram based, source code based, systems, object oriented, agent oriented, service oriented, component base software.

\section{INTRODUCTION}

Software development life cycle consist five phases. They are follows: (1) requirement analysis, (2) design, (3) coding, (4) testing and (5) maintenance. Testing consumes maximum time and effort and cost in comparison of other phases to the overall of a software when it come to existence. Testing can be dividing in two forms: black box testing, white box testing. Performance and reliability of software depend on the testing. Test cases are required to check weather software is working according to the requirement or not. Testing depends on the good test case. If the test cases have good quality then testing process will be good and performance of software will be good. In present time few methods are very famous and use by researchers and practitioner. These methods are path oriented, random method and heuristic approaches [1]. When software release, customer gives view of software performance. Before releasing the software, the performance of software check by testing and testing depends on the good test case [2]. So quality of test case should be good. There are many techniques which are used to yield the test cases, these techniques are unified modeling language, genetic algorithm, and state chart diagram.

\section{LITERATURE REVIEW}

This section describes software system and techniques which help to generate the test cases. This paper describes software system one by one. This paper divides the literature review in two parts.
1. Literature review of system

2. Literature review of techniques

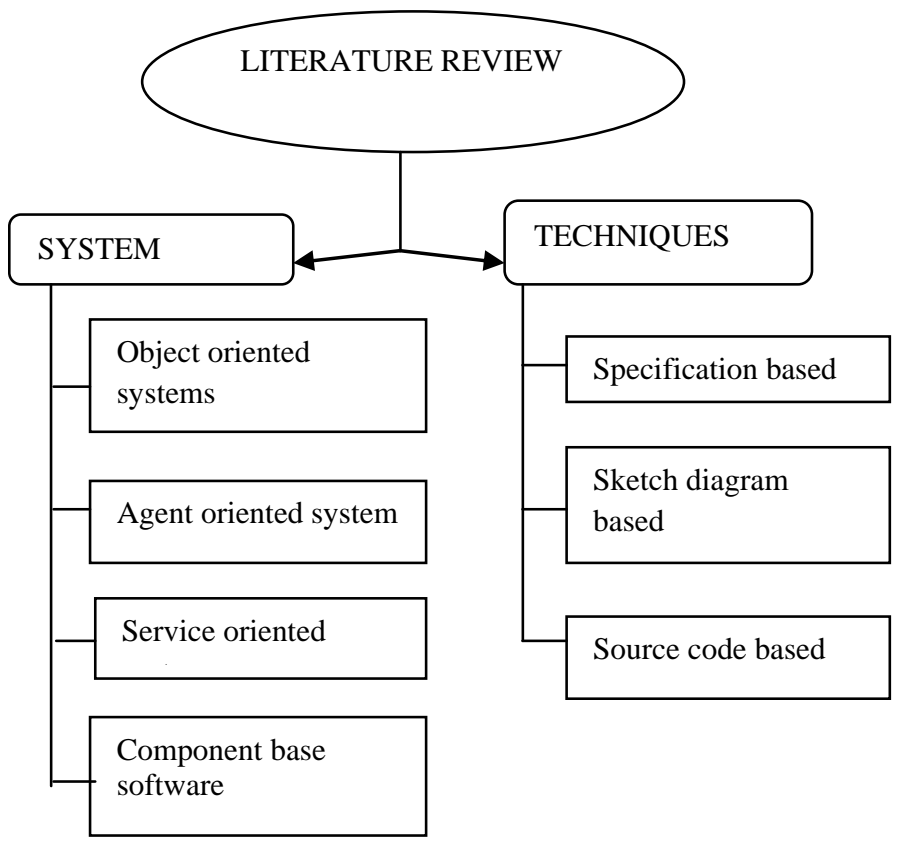

\subsection{Literature Review of System}

Object oriented system:V.mary sumalatha and G.S.V.P.Raju et al. [3] have proposed an approach for object oriented system. Test cases are generated by using the unified modeling language (UML) diagrams and genetic algorithm.

UML is basically used for the object oriented system. For test case generation, UML sequence diagrams are made by the help of unified modeling language. Various notations are used in sequence diagram. After creating the sequence diagram, convert the sequence diagram in sequence graphs. Assign weights to node in sequence graph. In this research paper, genetic algorithm applies to the sequence graph. With the help of fitness function, new generation selected in this research paper, all operation of genetic algorithm selection and crossover and mutation are used. Best test cases are selected in the end. In this research paper spider card games is taken and apply all rules for generating the test cases.

A.v.k shanthi and dr.g.mohan Kumar et al. [4] have proposed approach to automated test cases generation for object oriented software. In this paper UML (unified modeling language) is used for creating a suitable model and designing of software. UML is very famous in industry for creating the UML model and designing of software. Design specification technique has advantage that it allows test case generation 
early in software development life cycle. This paper has used the data mining concept. Tool is used in this research paper, which get the information from the UML class diagram. Genetic algorithm is used to generate an automated test case generation. A tree structure is created with the help of that information which are get by the UML class diagram. Cross over operator applies on the tree to discover all possible paths.

\section{Advantage:}

1. Test cases are easily generated in software development life cycle in the design specification technique.

2. with the help of UML (unified markup language), designs (class diagram) are easily created.

Creating the UML sequence diagram

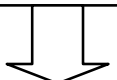

Convert the sequence diagram in sequence graph

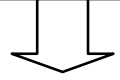

Apply genetic algorithm

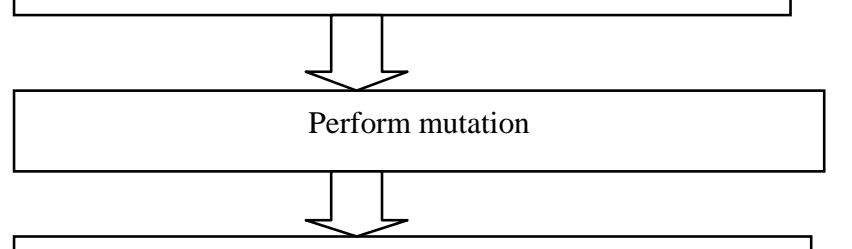

Calculated the fitness function and probability

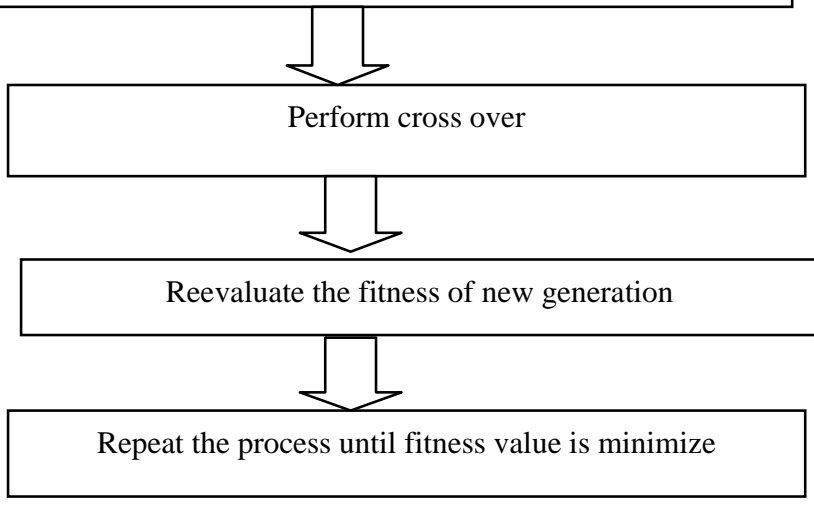

Figure1. Diagrammatic representation of the object oriented approach.

\subsection{Service Oriented Architecture}

Ebrahim shamsoddin-motlagh et.al [5] has proposed an approach for service oriented architecture. Service oriented architecture is newly architecture. This system reduces the gap between the business and software. Service oriented architecture has the different feature and specification in comparison of other software architecture. In this paper researcher, first create, the control flow graph of BPEL (business process execution language) file in the system and WSIG file is used to create sub graph of related services. With the help of genetic algorithm, it tries to create test cases, which will cover all sub graph of service in system. In this paper an approach is used to generate the test case automatically for BPEL language.
Challenges of this approach

1. Generated graph will be very large for the different services. It is very difficult to store and display on the screen.

2. Next challenge of this approach the SOA system is distributed system that has been established on the systems with different hardware and software. It is need to test the system with a quality of

3. platform to support

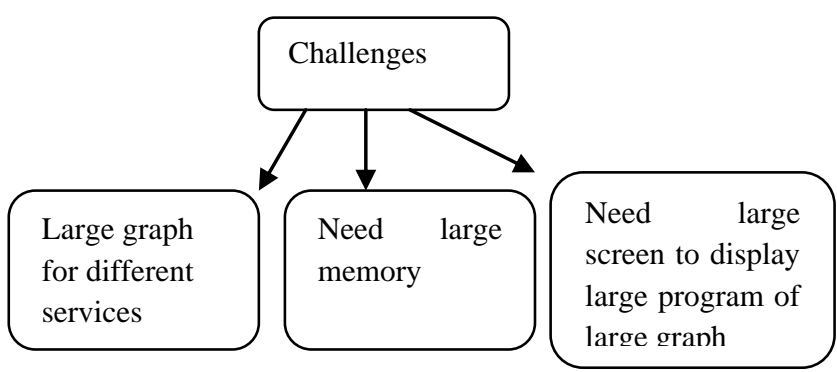

Figure2.Challenges of service oriented architecture

\subsection{Agent Oriented System}

N.siva kumar, K.Vivek anadan, A, Mohan et al. [6] have proposed an approach for agent based system. Agent oriented system has wide area for the research. Pole oriented approach is define in this research paper. This paper depends on the role of the agent and transforms the role diagram into the activity diagram. In this research paper, role diagram of user registration is describe, which is transform into activity diagram. All paths are covered by an activity graph which is validated by cyclomatic complexity. With the help of cyclomatic complexity test cases are generated. Role based approach discover the faults like as lacking in decision, lacking in loop and coordination lacking.

\section{Advantage \\ 1. Statement handling \\ 2. Loop handling. \\ 3. Code handling.}

Yacine kissoum and Zaidi sahnoun et al. [7] have proposed formal specification approach for test case generation for multi agent system. Formal specification approach uses the Maude algebraic language. MAL easily provides the explanation and internal behavior of each agent class. In this paper agent unified modeling language is used to cover all possible paths in activity and sequence diagram.

\subsection{Component -Based System}

Shaveta gupta and jimmy singal et al. [8] have proposed two approaches for automated test case generation using PETA tool and namely test case generation from UML activity diagram based on gray box method. Component based software engineering is depends on the components which are used to construct the software system. PETA is a java /eclipse based platform. Under this PETA tool we have to follow three steps.

1. Apply setting under this tool

2. Class diagram age generated

3. Finally test cases are generated

Neelam sirohi ,anshu parasharn et al.[9]:- 
This paper defines what is component based system? and what is the architecture of the component based system. Component based system depends on the component (which is called third party) which is used to make the component system. So the quality of the component should be good. Component based software engineering follows the rule, we can create new software by using the outdate software. Example of component model is enterprise java beans, component object model, and net model. This paper defines the various steps of component based system development [10]. Component based system is a new area for research and have a large space for research.

\section{TECHNIQUES}

We have various types of techniques for generating the test cases. They follow as (1) random approaches, (2) goal oriented technique, (3) specification based techniques, and (4) sketch diagram based technique, source code base technique [12]. In this section we describe the test case generation techniques.

Here we describe three techniques specification based technique, sketch based technique, source code base technique.

\subsection{Specification Based Technique}

To generate a set of test case from specification documents is called specification based techniques. Specification document are formal requirements specification and object constraint language specification [13], [14]. Specification method depends on the system is to do without having the knowledge how to implement it or how to do it [15]. Specification documents may be helped for output checking and may be helped to reduce to reduce the cost of testing. Specification based technique is better than non specification based techniques because it provide simple and formal approach to generate the functional test cases.

Antonio et.al [16] presented object constraint language (OCL) specification. OCL is the member of the UML 2.0. And it provides the specification of formal constraints in context of a UML model. Constraints are used to present constant of classes

There are many researchers who have worked on specification technique. Here we give brief review of the researchers since 1994 to 2015. [20] To [32].

Table 1.

\begin{tabular}{|l|l|l|}
\hline YEAR & $\begin{array}{l}\text { RESEARCHERS } \\
\text { NAME }\end{array}$ & $\begin{array}{l}\text { SPECIFICATION } \\
\text { TECHNIQUE (WORKING } \\
\text { OF RESEARCHES) }\end{array}$ \\
\hline 1994 & Weyuker & $\begin{array}{l}\text { Use Boolean specification } \\
\text { method. }\end{array}$ \\
\hline 1996 & $\begin{array}{l}\text { Black burn and } \\
\text { busser }\end{array}$ & $\begin{array}{l}\text { Provide a tool for critical } \\
\text { system, which are used to } \\
\text { generate the test case. }\end{array}$ \\
\hline 1997 & Kancherla & $\begin{array}{l}\text { Generating test templates } \\
\text { with the help of automated } \\
\text { theorem proving. }\end{array}$ \\
\hline 1999 & Cunning and & $\begin{array}{l}\text { They are used requirements } \\
\text { specifications for automatic } \\
\text { test case generation. they } \\
\text { generated automatic test } \\
\text { case for the real time } \\
\text { embedded system. }\end{array}$ \\
\hline
\end{tabular}

\begin{tabular}{|c|c|c|}
\hline & & $\begin{array}{l}\text { are based on the } \\
\text { specification based tests. }\end{array}$ \\
\hline 2000 & $\begin{array}{l}\text { Huaikou, M. and } \\
\text { L. Ling. }\end{array}$ & $\begin{array}{lll}\text { Using } & Z & \text { specification } \\
\text { method. } & & \end{array}$ \\
\hline 2001 & Tran & $\begin{array}{l}\text { Test generation using model } \\
\text { checking }\end{array}$ \\
\hline 2001 & $\begin{array}{l}\text { Rayadurgam, S. } \\
\text { and M.P.E. } \\
\text { Heimdahal }\end{array}$ & $\begin{array}{l}\text { Using formal requirement } \\
\text { models. }\end{array}$ \\
\hline 2002 & Jia X. and H.Liu & $\begin{array}{l}\text { Define different types of } \\
\text { testing of web application. }\end{array}$ \\
\hline 2003 & Jia X. and H.liu & $\begin{array}{l}\text { Used the method of formal } \\
\text { structured specification for } \\
\text { web application testing. }\end{array}$ \\
\hline 2006 & $\begin{array}{l}\text { Antonio, P., } \\
\text { P.Salas and } \\
\text { B.K.Aichering }\end{array}$ & $\begin{array}{l}\text { Present a mutation approach } \\
\text { for OCL. }\end{array}$ \\
\hline 2006 & $\begin{array}{l}\text { Nilsson } \\
\text {,R.,J.Offutt and } \\
\text { J.mellin }\end{array}$ & $\begin{array}{l}\text { Using mutation based testing } \\
\text { method }\end{array}$ \\
\hline 2007 & Harman & $\begin{array}{l}\text { The current state and future } \\
\text { of search based software } \\
\text { engineering. }\end{array}$ \\
\hline 2009 & $\begin{array}{l}\text { Shen ,X.Wang } \\
\text {,Q, Wang P and } \\
\text { Zhou,B. }\end{array}$ & $\begin{array}{l}\text { Presented } \\
\text { generation of test cases } \\
\text { based on GATS. }\end{array}$ \\
\hline 2010 & $\begin{array}{l}\text { Object } \\
\text { management } \\
\text { group }\end{array}$ & $\begin{array}{l}\text { Presented object constraint } \\
\text { language specification }\end{array}$ \\
\hline 2010 & $\begin{array}{l}\text { Brucker } \\
\text {,A.D,Krieger, } \\
\text { M.P; Longuet } \\
\text {,D.and } \\
\text { WOLFFB. }\end{array}$ & $\begin{array}{l}\text { presented specification } \\
\text { based test case generation } \\
\text { method for UML /OCL }\end{array}$ \\
\hline 2012 & $\begin{array}{l}\text { Cabot , J. , and } \\
\text { Gogolla, M. }\end{array}$ & $\begin{array}{l}\text { A definitive guide formal } \\
\text { methods for model driven } \\
\text { engineering }\end{array}$ \\
\hline 2012 & $\begin{array}{l}\text { Elberzhager , F. } \\
\text { Rosbach , A., } \\
\text { Munch , J.and } \\
\text { Eschbach, R. }\end{array}$ & $\begin{array}{l}\text { Presented reducing test } \\
\text { effort. A systematic mapping } \\
\text { study on existing } \\
\text { approaches. }\end{array}$ \\
\hline 2015 & $\begin{array}{l}\text { A.Jalila, } \\
\text { D.J.Mala, } \\
\text { M.Eswaran }\end{array}$ & $\begin{array}{lrr}\text { Presented } & & \text { early } \\
\text { identification of } & \text { software } \\
\text { defects using } & \text { OCL } \\
\text { predicates to } & \text { improve } \\
\text { software quality. } & \end{array}$ \\
\hline
\end{tabular}

Survey of Spec. tech.

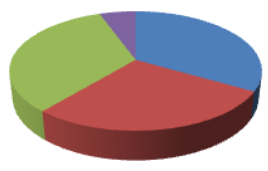

- 1994-2000

- 2000-2006

-2006-2012

Fiigure3 .Survey of specification based technique. 


\subsection{Sketch Diagram Based Test Case Generation Technique}

It is used to generate the test cases for the model diagram. Model diagram are such as UML, USE CASE diagram, UML state diagrams. This technique is used for traditional and web based application [17] [18] [19]. Many researchers have worked on this technique. Here we are giving brief review on this technique. [33] TO [44]

Table2.

\begin{tabular}{|c|c|c|}
\hline YEAR & $\begin{array}{l}\text { RESEARCHER } \\
\text { NAME }\end{array}$ & RESEARCH FIELD \\
\hline 2000 & $\begin{array}{lr}\text { Cavarra, A., } & \text { C. } \\
\text { Crichton, } & \text { J. } \\
\text { Davies, } & \text { A. } \\
\text { Hartman, T. Jeron } \\
\text { and L. Mounier }\end{array}$ & $\begin{array}{l}\text { Automatic test case } \\
\text { generation with the help of } \\
\text { UML. }\end{array}$ \\
\hline 2000 & $\begin{array}{l}\text { Kung, D.C, C.H. } \\
\text { Liu, and P. Hsia }\end{array}$ & $\begin{array}{l}\text { Presented a model that is } \\
\text { object oriented for web } \\
\text { application. }\end{array}$ \\
\hline 2000 & $\begin{array}{l}\text { Ryser, J. and M. } \\
\text { Glinz }\end{array}$ & $\begin{array}{l}\text { They presented a method } \\
\text { for system test. And also } \\
\text { derived the test case } \\
\text { systematically. }\end{array}$ \\
\hline 2001 & Heumann, J. & $\begin{array}{l}\text { Presented a use case } \\
\text { method for generating test } \\
\text { cases. }\end{array}$ \\
\hline 2001 & $\begin{array}{l}\text { Ibrahim K. El-Far } \\
\text { and James A. } \\
\text { Whittaker }\end{array}$ & $\begin{array}{l}\text { Presented MBT } \\
\text { Method and also } \\
\text { Include the FSM }\end{array}$ \\
\hline 2003 & $\begin{array}{l}\text { Manish Nilawar, } \\
\text { Sergiu Dascalu }\end{array}$ & $\begin{array}{l}\text { Explain unified modeling } \\
\text { language and use this } \\
\text { approach for testing the } \\
\text { web application }\end{array}$ \\
\hline 2004 & $\begin{array}{l}\text { Anneliese A. } \\
\text { Andrews, Jeff } \\
\text { Offut Roger T. } \\
\text { Alexander }\end{array}$ & $\begin{array}{l}\text { Testing Web Applications } \\
\text { by Modeling with FSMs. }\end{array}$ \\
\hline 2005 & $\begin{array}{l}\text { Avik Sinha, Carol } \\
\text { Smidts }\end{array}$ & $\begin{array}{l}\text { Present a technique which } \\
\text { is model based and } \\
\text { increase testing of domain } \\
\text { specific. }\end{array}$ \\
\hline 2006 & $\begin{array}{lr}\text { Santiago, } & \text { V., A, } \\
\text { S, M. } & \text { DO- } \\
\text { Amaral, } & \text { N.L. } \\
\text { vijay } & \text { kumar, } \\
\text { M.D.F. } & \text { M. } \\
\text { attiello-Francisco, } \\
\text { E. Martins and } \\
\text { O.C. Lopes }\end{array}$ & $\begin{array}{l}\text { Using state chart generate } \\
\text { test case automatically. }\end{array}$ \\
\hline 2006 & $\begin{array}{l}\text { Shams, M., D. } \\
\text { Krishnamurthy } \\
\text { and B. Far }\end{array}$ & $\begin{array}{l}\text { For testing the } \\
\text { performance of web } \\
\text { application they used } \\
\text { model based approach. }\end{array}$ \\
\hline 2007 & $\begin{array}{l}\text { A.Z. Javed, P.A. } \\
\text { Strooper, } \\
\text { Watson. }\end{array}$ & $\begin{array}{l}\text { Using model } \\
\text { architecture for } \\
\text { automatic test case } \\
\text { generation. }\end{array}$ \\
\hline 2008 & $\begin{array}{l}\text { Reza, H., ogaard, } \\
\text { K. and Malge, A. }\end{array}$ & Use the state charts. \\
\hline
\end{tabular}

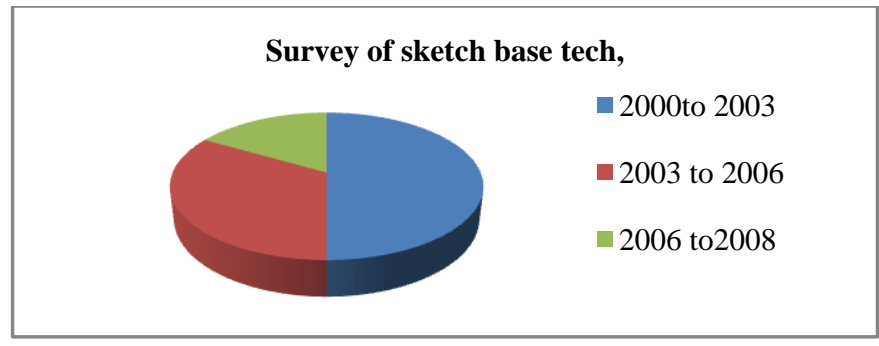

Figure4. Survey of sketch based technique.

\subsection{Source Code Based Test Case \\ Generation Technique}

Source code based technique based on the control flow information. Control flow information is used to recognized (point out) a set of path to be covered and generated test cases for these path [20]. In this section we described test case generation technique (source code based) which is used by many researchers. [45] TO [51].

Table3.

\begin{tabular}{|c|c|c|}
\hline YEAR & $\begin{array}{l}\text { AUTHOR } \\
\text { NAME }\end{array}$ & RESEARCH FIELD \\
\hline 1995 & $\begin{array}{lr}\text { Avritzer, } & \text { A } \\
\text { And E. } & \text { J } \\
\text { Weyuker } & \end{array}$ & $\begin{array}{l}\text { Presented load test suites. } \\
\text { And check the resulting } \\
\text { software. }\end{array}$ \\
\hline 1990 & Korel, B. & $\begin{array}{l}\text { Automated software test } \\
\text { data generation. }\end{array}$ \\
\hline 1999 & $\begin{array}{l}\text { Pargas, R.P, M } \\
\text { J. Harrold and } \\
\text { R.R Peck }\end{array}$ & Using genetic algorithms. \\
\hline 1999 & $\begin{array}{l}\text { Yang, J.T, J.L. } \\
\text { Huang, F. J. } \\
\text { Wang and } \\
\text { W.C. Chu }\end{array}$ & $\begin{array}{l}\text { Use CFG to create the web } \\
\text { application. }\end{array}$ \\
\hline 1998 & $\begin{array}{l}\text { Neelam Gupta, } \\
\text { Aditya P } \\
\text { Mathur, Mary } \\
\text { Lou Soffa } \\
\end{array}$ & $\begin{array}{l}\text { Using iterative relaxation } \\
\text { methods generate the } \\
\text { automated test cases. }\end{array}$ \\
\hline 2003 & $\begin{array}{l}\text { Beydeda and } \\
\text { gruhn }\end{array}$ & $\begin{array}{l}\text { Proposed an approach } \\
\text { BINTEST Binary search } \\
\text { based test case generation. }\end{array}$ \\
\hline 2008 & $\begin{array}{l}\text { D.A. Turner, } \\
\text { M. Park } \text {,J. } \\
\text { Kim and J. } \\
\text { Char }\end{array}$ & $\begin{array}{l}\text { Presented activity oriented } \\
\text { approach for testing web } \\
\text { application }\end{array}$ \\
\hline
\end{tabular}

survey of Source code base tech

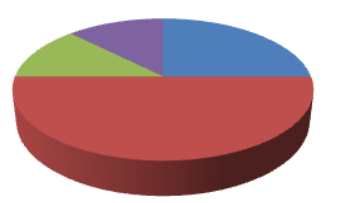

-1990to1995

-1995to2000

-2000to2005

- 2005to2008

Figure5. Survey of source code base technique

\section{CONCLUSION}

This research paper is based on test case generation technique and systems. In this research paper we have described the techniques year wise. We have represented the techniques 
with the help of pie chart. We have represented the brief literature survey of system. In this research paper we have represented the three techniques which are used to generate the test case generation.

\section{REFERENCES}

[1] Wang Xibo and $\mathrm{Su} \mathrm{Na}$, "Automatic test data generation for path testing using genetic algorithm" in proc. $3^{\text {rd }}$ International Conference on Measuring Technology and Mechantronics Automation (ICMTMA), 2011, PP. 596599.

[2] M.Prasanna, S.NSivanandam, R.Venkatesan and R.Sundarrajan "Asurvey on automatic test case generation"Academic Open Internet Journal Vol.15, 2015.

[3] V.Mary Sumalatha, G.S.V.P.Raju "Object oriented test case generation technique using genetic algorithms" International Journal of Computer Application Vol.61No.20, jan.2013.

[4] A.V.K.Shanthi and Dr G.Mohan Kumar "Automated test cases generation for object oriented software" Indian Journal of Computer Science and Engineering (IJCSE) Vol.2 No.4 aug-sep.2011 ISSN 0976-5166.

[5] Ebrahim Shamsoddin Motlagh "Automatic test case generation for orchestration languages at service oriented architecture" International Journal of Computer Application (0975-8887) Vol.80-No.7, oct.2013.

[6] N.Sivakumar. K.Vivekanandan, A.Mohan, "Role oriented test case generation for agent based system" International Journal on Computer Science and Engineering (IJCSE) Vol.5-No.02, 2feb.2013 ISSN 0975-3397.

[7] Yacine Kissoum and Zaidi Sahnoun "Test cases generaton for multi-agent system using formal specification"

[8] Shaveta Gupta and Jimmy Singla "A component based approach for test case generation" International Journal of Technology and Knowledge Management Vol.5-No.2, pp.239-243.

[9] Neelam Sirohi, Anshu Parashar "Component based system and testing technique" International Journal of Advanced Research n Computer and Communication Engineering Vol.2, Issue 6, jun.2013.

[10] Ivica Crnkovic, "Component-Base Software Engineering - New Challenges in Software development", journal of computing and Information Technology -CIT 11, 3,151161, 2003, pp.151-160.

[11] Prasanna, M. S.N. Sivanandam, R. Venkatesan and R. Sundarrajan, " A survey on automatic test case generation" Acad. Open Internet J., 2005, 15:1-6 .

[12] Cunning, S.J. and J.W.Rozenblit, "Automatic test case generation from requirements specifications for real time embedded systems" IEEE Int. Conf. Syst. Man Cybernetics, 1999, 5: 784-789.

[13] Tran, H. "Test generation using model checking" European Conference on Software Maintenance and Reengineering, CSM 2001, http://www.cs.toronto.edu/ chechik/courses00/csc2108/p rojects/4.pdf 2001.
[14] Nicha Kosindrdecha and Jirapun Daengdej "A test case generation technique and process" Journal of Software Engineering 4(4) 265-287 2010, Academic Journal Inc., 2010 ISSN 1819-4311.

[15] Antonio, P., P. Salas and B.K. Aichernig " Automatic test case generation for 0CL: A mutaton approach" proceedings of $5^{\text {th }}$ International Conference Quality Software, an. 2006, IEEE Computer Society, pp : 64-71 2006.

[16] Heumann, J., “ Generating test cases from use cases" Rational Software http://www.ibm.com/developerworks/rational/library/con tent/rationalEdge/jun01/GeneratingTestCaseFromUseCas esJune01.pdf 2011.

[17] Javed, A.Z, P.A. Strooper and G.N. Watson, "Automated generation of test cases using model-driven architecture" Proceeding of the Second International Workshop on Automation of Test, may 20-26, Minneapolis, USA, 2007,150-151.

[18] Sinha, A. and C.S. Smidts "Domain specific test case generation using higher ordered typed languages from specification" Ph.D. Thesis, University of Maryland 2005.

[19] Nicha Kosindrdecha and Jirapun Daengdej "A test case generation technique and process" Journal of Software Engineering 4(4) 265-287 2010, Academic Journal Inc., 2010 ISSN 1819-4311.

[20] Weyuker, E., T. Goradia and A. Singh, "Automatically generating test data from a boolean specification" IEEE.Trans.Software Eng., 199420 353-363.

[21] Blackburn, M. And R. Busser, " T-VEC: A tool for developing critical systems." Proceeding of the Annual Conference on Computer Assurance,(ACCA'96),IEEE Computer Society Press, 1999 pp: 237-249.

[22] Kancherla, M.P., 1997.Generating test templates via automated theorem proving. Technical Report, NASA Ames Research Center.

[23] Cunning, S.J And J.W. Rozenblit, 1999. Automatic test case generation from requirements specification for real time embedded systems. IEEE Int. Conf. Syst. Man Cybernetics, 5: 784-789.

[24] Offutt, A.J., Y. Xiong and S. Liu, 1999. Criteria for generating specification-based tests. Proceedings of the $5^{\text {th }}$ International Conference on Engineering of Complex Computer System, Oct. 18-22, Washington, USA., pp: 119-119.

[25] Huaikou, M. And L. Ling, " A test class framework for generating test cases from $\mathrm{Z}$ specifications" Proceedings of $6^{\text {th }}$ IEEE International Conference on Complex Computer Systems,Sept. 11-15, Tokoy, Japan, 2000, pp. 164-164.

[26] Tran, H., "Test generation using model checking" European Conference on Software Maintenance and Reengineering, CSMR2001 http://www..cs.toronto.edu/ chechik/courses00/csc2108/ projects/4.pdf.

[27] Rayadurgam, S.and M.P.E. Heimdahl, “ Test -sequence generation from formal reuriment models." Proceedings of the $6^{\text {th }}$ IEEE International Symposium on High 
Assrance System Engineering, Oct. Boca Raton, Florida, pp:23-23, 2001, 22-24.

[28] Jia, X. and H. Liu, "Rigours and automatic testimg of web applications" Proceedings of $6^{\text {th }}$ IASTED International Conference on Software Engineering and Application, May 2002, Hnolulu, USA., pp: 654-668.

[29] Jia, X. and H. Liu and L. Qin, "Formal structured specification for web application testing" Proceedings of thr Midwest Software Engineering Conference, (MSEC'03), Chicago, USA., 2003, pp:88-97.

[30] Antonio, P., P. Salas and B.K. Aichering "Automatic test case generation for OCL : A mutation approach " PROCEEDING OF $5^{\text {th }}$ International Conference Quality Software, Jan. 2006, IEEE Computer Society, pp: 64-71.

[31] Nilsson, R., J. Offutt and J.Mellin, "Test acse generation for mutation based esting of timeliness." Electronic Notes Theor. Comput. Sci., 164: 97-114.

[32] Mark harman "The current state and futur of search based software engineering" Proceeding FOSE 07, 2007, Future of Software Engineering, IEEE Computer Society of Washington, DC, USA.2007, 342-357.

[33] Cavarra,A., C. Crichton, J. Davies, A. Hatman, T. Jeron and L. Mounier, "Using UML for automatic test generation" Oxford Univesity Computing Laboratory, Tools and Alllgorithms for the Construction and Analysis of Systems, TACAS'2000.

[34] Kung, D.C., C.H. Liu and P. Hsia "An object oriented web test model for testing web applications" Proceedings of the First Asia Pacific Conference on Quality Sofware,(APCQS'00), Los Alamitos, 2000, pp: 111-111. systematically derive

[35] Ryser, J. and M. Glinz, "SCENT:A Method employing scenarios to test cases for system test." Technical Report, http://portal.acm.org/citation.cfm?id=901553.

[36] Heumann, J., "Generating test cases from use cases" Rational Software. http://www.ibm.com/developerworks/rational/library/con tent/RationalEdge/jun01/GeneratingTestCasesFromUseC asesJune01.pdf.

[37] El-Far, I.K. and J.A. Whittaker, "Model based software testing" http://143.225.25.115/ flammini/materiale/Modelbased\%20Testing/ModelBasedSoftwareTesting.pdf. 2001.

[38] Nilawar, M. and S.Dascalu, "A UML-based approach for testing web applications" M.Sc. Thesis, University of Nevada, Reno. 2003.

[39] Andrews, A., Offutt, J., and Alexander, R., 2005. Testing Web Applications byModeling with FSMs, Journal of Software System and Modeling, vol. 4, no. 2, pp.326345 .
[40] Sinha, A. and C.S. Smidts, "Domain specific test case generation using higher ordered typed languages from specification" Ph.D. Thesis, University of Maryland, 2005.

[41] Santiago, V., A.S.M. Do- Amaral, N.L. Vijay kumar, M.D.F., M. attiello-Francisco, E. Martins and O.C. Lopes, "A practical approach for automated test case generation using state charts." Proceedings of the $30^{\text {th }}$ Annual International Computer Software and Applications Conference, Sept. 17-21, IEEE Computer Society, pp: 183-188.

[42] Shams, M., D. Krishnamurthy and B. Far, "A model based approach for testing the performance of web applications" Proceeding of the $3^{\text {rd }}$ International Workshop on Software Quality Assurance, Nov.6, New York, USA. 2006, pp: 54-61.

[43] Javed, A.Z., P.A. Strooper and G.N. Watson, "Automated generation of test cases using model- driven architecture." Proceeding of the Second International Workshop on Automation of Software Test, May 20-26, Minneapolis, USA, 2007, 150-151.

[44] Reza, H., K. Ogaard and A. Malge "A model based testing technique to test web applications using state charts" Proceeding of $5^{\text {th }}$ International Conference on Information Technology: New Generations, April 7-9, Las Vegas. 2008, pp: 183-188.

[45] Avrizer, A. and E.J. Weyuker, "The automatic generation of load test suites and the assessment of the resulting software" IEEE Transaction Software Eng., 1995 , 21: 705-716.

[46] Korel, B., "Automated software test data generation." IEEE Trans. Software Eng., 1990, 16: 870-879.

[47] Pargas, R.P., M.J. Harrold and R.R. Peck, "Test data generation using genetic algorithms" Software Testing Verification Reliability, 1999, 9: 263-282.

[48] Yang, J.T., J.L. Huang, F.J. Wang and W.C .Chu, "Constructing control flow based testing tools for web application" $11^{\text {th }}$ Software Engineering and Knowledge Engineering Conference(SEKC'99), June 1999.

[49] Gupta, N., A.P. Mathur and M.L. Soffa, "automated test data generation using an iterative relaxation method" ACM SIGSOFT Software Eng. Notes, 1998, 23: 231244.

[50] Beydeda, S. and V. Gruhn, " BINTEST-Binary search based test case generation" Proceedings of Computer Software and Application Conference, Nov. 2003, Leipzing Univ., Germany Leipzig Univ., Germany, pp:28-33.

[51] Tuner, D.A., M .Park, J. Kim and J. Chae, "An activity oriented approach for testing web applications" Proceeding of the $23^{\text {rd }}$ IEEE/ACM International Conference on Automated SoftwareEngineering, Sept. 15-19, Washington, USA., 2008, pp: 411-414. 